Forthcoming in the Journal of Comparative Economics

Migration and Rural Poverty in China

Yang Du

Institute of Population and Labor Economics

Chinese Academy of Social Sciences

Beijing 100732

China

Albert Park

Department of Economics

University of Michigan

Ann Arbor, MI 48109

USA

Sangui Wang

Institute of Agricultural Economics

Chinese Academy of Agricultural Sciences

Beijing 100081

China

September 2005

Correspondence author: Albert Park, Department of Economics, University of Michigan, 611 Tappan Street, Ann Arbor, MI 48109-1220, email: alpark@umich.edu. On leave during academic year 2005-2006, please confirm current address before mailing. 


\title{
Migration and Rural Poverty in China
}

\begin{abstract}
We analyze two complementary household datasets from China's poor areas to examine whether the poor migrate and whether migration helps the poor. We find an inverted-U- shaped relationship between household endowments and the likelihood of migration. Over time, the poor are more likely to migrate. Using household panel data and taking prior village migration networks as an instrument, we find that having a migrant increases a household's income per capita by 8.5 to 13.1 percent, but that the overall impact on poverty is modest because most poor people do not migrate. Migrants remit a large share of their income and the amount of these remittances is responsive somewhat to the needs of other family members.

JEL codes: I32, J61, O15, O53
\end{abstract}




\section{Introduction}

From the beginning of the economic reforms, China has achieved remarkable success in poverty reduction (Chen and Ravallion, 2004; Park and Wang, 2001). Large initial reductions in poverty resulted from the rapid rural productivity growth associated with the return to family farming after many years of collective agriculture. However, from the mid-1980s, China's economic growth has been driven primarily by rapid industrialization and urbanization, especially in coastal regions. Currently, rapid structural change in which labor is leaving agriculture for higher returns in nonagricultural sectors is ongoing in China. Because the migration of poor households has the potential to reduce poverty considerably, international development organizations include labor-mobility-enhancement components in their rural development projects (World Bank, 2001). However, little empirical evidence is available on the ability of the poor to take advantage of migration opportunities or on the benefits of such migration for the poor remaining behind.

There are reasons to be concerned that the rural poor may not be sharing equally in the benefits of China's rapid economic growth. Two thirds of China's poor households are located in western regions, which are remote from the booming coast (World Bank, 2001). Distance increases the costs of migration and makes job search more difficult. Both rural-urban and inter-regional inequality have increased over time, indicating that substantial barriers to labor mobility remain (World Bank, 1997). Despite recent reform initiatives, China's residential permit (hukou) system continues to divide urban and rural populations. In addition, poor people tend to be less 
educated so that they may be under-qualified for many jobs in the increasingly skilloriented economy.

Our objective is to shed empirical light on two fundamental issues related to the contribution of labor migration to poverty alleviation. First, we investigate whether poor people are able to migrate. Second, if migration does occur, we analyze its effects on the welfare and poverty status of migrants and other family members. The large literature on migration in China does not focus on poor areas or the implications of migration for poverty reduction. ${ }^{1}$ In section 2 , we introduce the data and define key terms used in the analysis. A description of structural change and migration trends in China is provided in section 3. Section 4 analyzes the determinants of migration from poor regions and examines whether or not the poor migrate. In section 5, we empirically estimate the effect of migration on household incomes and poverty, and study the remittance behavior of migrants and the implications of remittances for the welfare of non-migrant family members. Section 6 concludes. We find that structural change is becoming more inclusive of migrants from poor regions over time, migration significantly increases family income, and migrants share a large share of their income with family members living in poor areas. However, the poorest individuals living in poor regions are less likely to migrate, so that migration has played only a modest role in reducing poverty.

\section{Data and Definitions}


We use two datasets; the first is the China Poverty Monitoring Survey (CPMS) from 1997 to 2001. The CPMS is a panel household survey conducted by the National Bureau of Statistics (NBS) each year in all nationally designated poor counties. Its strength is its comprehensive coverage of households in all of China's poor regions over time. The CPMS includes 60 to 100 households each year in all 532 nationally designated poor counties in China, resulting in a sample size of about 50,000 households per year. From 1997 to 2001, the CPMS followed the same households over time. One of the disadvantages of its panel design is that the sample ages over time; hence younger households are increasingly under-represented. Because younger households are more likely to migrate, both the level, and the rate of increase, of migration are understated in the CPMS.

The second dataset is the China Rural Poverty Survey (CRPS), which is a household survey with a panel component. The CRPS was conducted in 1997 and 2000 in four poor counties located in four different provinces in western China. The advantage of the CRPS is in the detail of the questions asked about migration and remittances. In 1997, the CRPS sampled 442 NBS rural households in 6 nationally designated poor counties located in 6 different provinces. The 2000 survey sampled 582 households having 2,567 adults of working age in 4 of the same poor counties surveyed in 1997 in western China. In each county, 15 households were sampled in each of ten villages. ${ }^{2}$ The sampling probabilities for new households included in the 2000 survey were designed to create a representative sample. When making comparisons over time, we restrict our attention to the 290 households in the four 
counties that were surveyed in both samples. Together, these two datasets are complementary in that one provides breadth and the other provides depth.

Poor counties in China are determined by economic indicators, especially rural income per capita, and political considerations, e.g., whether the county was a revolutionary base area during the early Communist period or whether it has a large share of ethnic minority citizens. The regional distribution of China's poor counties is described in Table A1 of the Appendix. Not surprisingly, most poor counties are located in the western and central parts of the country. Few poor counties exist in the southeast and northeast of China.

The CPMS contains household information on income and expenditures, household size, number of laborers, number of laborers with different levels of education, number of laborers who are migrants, cultivated land, whether the area is hilly or mountainous, distance to nearest market, household assets, and whether the area is a revolutionary base or minority area. The NBS defines household members to include individuals who lived in the household for six months or more in the past year or those living mainly outside the household but whose economic life is closely tied to the household in that most of their income is pooled. The standard practice in many household surveys is to use the former, but not the latter, criterion to define household membership. In the CPMS, a migrant is defined as a household laborer who spent any time in the past year living outside the home for work. Laborers include men aged 16 to 60 and women aged 16 to 55 who are able to work. In this paper, we define long-term migrants to be those who migrated for 6 months or longer in the past 
year and short-term migrants to be those who migrated for less than 6 months. Under standard practices, long-term migrants would not be considered household members but, using the CPMS data, migrants include some, but not all, of the long-term migrants from a given rural area. ${ }^{3}$

In the CRPS, a migrant is defined as any family laborer who spends time during the year living outside the township to engage in economic activity. Labor is defined equivalently in both samples. Only wage jobs lasting more than 10 days are reported in the survey. The CRPS follows standard practice in defining households to include only those individuals who lived at home for at least 6 months in the past year. With respect to long-term migrants, the 1997 wave of the CRPS contains information on the work status and location of all non-resident spouses and unmarried children of household heads, but it has no detailed information on jobs and wages. The 2000 wave includes more detailed information on non-resident family members, including jobs, wages, and remittances. In this paper, we define family to include all resident members of the household and the household head, his or her spouse, and all unmarried children of the household head regardless of residency. Thus, the family includes long-term migrants who are likely to be tied closely to the household. For studying migration behavior, the family is considered to be a more relevant unit of observation than the household. ${ }^{4}$

\section{Structural Change and Migration Trends}


To provide institutional context, we first describe the overall structural changes occurring in China. Table 1 presents official data on the percentage of employed persons working primarily in the non-agricultural sector, by region, in selected years from 1993 to $2002 .^{5}$ We are particularly interested in comparing the western regions in which the majority China's poor households are located, to the other regions. In 1993, the southwest and northwest had the lowest shares of labor in the non-agricultural sector at 29.3 and 39.1 percent, respectively. The shares in both regions increased modestly from 1993 to 1997, but much more rapidly thereafter, reaching 38.4 and 44.1 percent, respectively, by 2002 for a nine-year increase of about 9 percent in the southwest and 5 percent in the northwest. Over the same time period, the share of non-agricultural labor increased by 6.6 percent in the east and by 5.3 percent in central China but it actually decreased by more than 6 percent in the northeast. Thus, the shift of labor out of agriculture in western regions was greater or comparable in magnitude to that in other regions measured as a fraction of the labor force, but it was much faster if measured by the growth rate of the non-agricultural labor force because the changes started from a lower base. After 1997, structural change by any measure was faster in the western provinces than in other regions. More striking evidence of structural change comes from rural household surveys, conducted annually in all provinces by the NBS, based on self-recorded diaries of all household income and expenditures. These surveys are comparable with the CPMS in terms of the survey instrument and the definitions of variables. Table 2 indicates that, after little change from 1993 to 1997, the share of rural household 
income from wages virtually doubled from 1997 to 2002 in western regions, with the most dramatic increases occurring from 2000 to 2002. These increases were larger than in other regions, whether measured by changes in absolute shares or growth rates. By 2002, the wage share of income in western rural areas was comparable to that of other regions in China, except for the East. Wages exhibit considerably more change than employment partly because much migration activity is part-time or seasonal. Thus, official employment numbers may underestimate substantially the share of time being spent in non-agricultural pursuits, as discussed by Meade and Rawski (1998).

Taken together, the evidence on employment and wages suggests that, after many years in which poor regions remained relatively wedded to agriculture compared to the rest of China, structural changes in poorer western provinces began to accelerate after 1997. Of course, such structural change may not be associated with migration if non-agricultural employment opportunities are created locally. However, the low population density and high transportation costs of rural mountainous regions have hampered industrial growth severely so that migration is likely to be an important part of these structural changes. Two caveats with respect to these trends are required. First, even if migration is increasing in the western provinces in which many poor people live, poor households in those areas may not be benefiting from it. If members in better-off households are more likely to migrate, inequality would be exacerbated and regional poverty would not be alleviated. Second, these trends are likely to underestimate the true degree of structural change because the employment of permanent or long-term migrants who have moved from one province to another 
are counted in the destination province but not in the province of origin. In particular, rural income data exclude the earnings of many long-term migrants living in urban areas. $^{6}$

The 2000 census provides additional evidence on migration patterns because it asks about where individuals currently live and the location of their residence permit (hukou). We define the rural migration rate to be the share of the population having a rural hukou in a particular region who report that their hukou is in a different township than where they are currently living. The census records only individuals who have lived in their current location for more than 6 months so that it measures only long-term migration. In Table 3, we present migration rates by region and destination based on the 2000 census data. According to these data, significant differences in long-term migration patterns arise in southwest and northwest China, with people in the southwest being more likely to migrate long term and to distant locations.

The best information on trends in rural migration, including short-term migration, is found in the annual rural migration survey conducted jointly by the Ministry of Agriculture, the Ministry of Labor, and the NBS. However, the survey has been conducted only since 1999 and regional breakdowns are not reported. Nonetheless, the increase in migration is dramatic, from 52 million persons in 1999 to 98 million persons in 2003. In addition, the number of people migrating to another province increased from 21 million to 40 million during this four-year period, as Cai, Park, and Zhao (2005) report. 
The survey data in both the CPMS and CRPS cover the period from 1997 when structural change accelerated. Table 4 reports the percentage of rural households in poor counties with at least one migrant from 1997 to 2001 based on the CPMS data. For all poor counties nationwide, the share of households with migrants increased modestly from 23.0 percent to 26.4 percent over this period. Because there are so few poor counties in the East and Northeast, we do not report separate statistics for those regions. Instead we focus on the two western regions and report the migration shares for households in poor counties in each province of those regions. Once again, we find a notable contrast in the migration trends in southwest and northwest China from 1997 to 2001. The share of households with migrants in poor counties in the northwest increased from 18.8 percent to 32.4 percent, but migration remained stagnant in the southwest at 21 to 22 percent of all households. ${ }^{7}$ The higher migration frequency in the northwest is at odds with census data, which show higher long-term migration rates from southwest China than from northwest China. This discrepancy may indicate that migration from the northwest is more likely to be shortterm or seasonal or that migration from non-poor counties in the northwest is much less than from non-poor counties in the southwest. Differences in the patterns of long-term and short-term migration suggest that caution should be used in inferring overall migration trends from census data and attention should be paid to the precise definition of migration in the datasets.

In the CRPS data, the percentage of families with at least one migrant increased from 39.9 percent in 1997 to 51.1 percent in 2000. Over the same period of 
time, the share of family laborers that migrated increased from 19.9 percent to 25.0

percent. The four counties in the CRPS have both poorer endowments and more migration than the full sample of CPMS counties, as Table A2 in the Appendix records. Hence, although less representative, the CRPS data are well-suited to investigating the relationship between migration and poverty. To summarize, China's official employment and income statistics indicate that structural change is moving labor off the farm rapidly and that this process has accelerated in recent years. Evidence from various data sources suggests that long-term migration has been greater in the southwest, while short-term migration has accelerated much faster in the northwest.

\section{Characterizing Migration}

Even though rural migration has increased substantially in recent years, migrants may not belong to the poorest households. In Table A2, we present summary statistics for households in poor areas with and without migrants. According to the data, migrant households are better-educated, more distant from markets or townships, have more household members and more laborers but fewer children and less land. Thus, migration is related positively to some household endowments, namely, education and labor, but negatively to others, namely, land and closeness to markets. Hence, the relationship between migration and the wealth of households is ambiguous. Because the CPMS survey does not distinguish which individuals within households migrate, we use the CRPS data to investigate the 
correlation between individual attributes and migration. Table A3 reports migration rates by gender, education, and age. The male migration rate increased from 26.9 percent in 1997 to 34.7 percent in 2000, while the female migration rate increased from 12.5 percent to 14.2 percent over the same period. The faster growth of male migration is due mainly to increased migration by educated men and older men. Differences were smaller for younger cohorts, but migration was still greater for men. In earlier studies of migration in China, Zhao (1999) and Rozelle et al. (1999) also find that men migrate more than women. However, recent research by Zhang, deBrauw, and Rozelle (2004) and deBrauw (2004) indicates that men and women have similar rates of migration in much of rural China. These studies also report a high rate of migration among younger persons, especially women. Zhang, deBrauw, and Rozelle (2004) find that 75 percent of young men and women migrate in a broadly representative sample of rural households. This is more than two times greater than the estimated migration rate of young persons using the CRPS survey. According to the CRPS data, educated persons are much more likely to migrate in 2000, but such a relationship is less obvious in 1997 for men. Zhang, Huang, and Rozelle (2002) and deBrauw et al. (2002) identify the increasing importance of education in gaining access to off-farm activities.

To investigate the determinants of household migration decisions and their change over time more formally, we estimate conditional logit models using the first and last years of the CPMS data. For 1997 and 2001, we estimate two specifications. This first takes account of county fixed effects; the other includes village fixed effects. 
In the former, we use geographic variables, i.e., topography and distance to the nearest market. In the latter, we avoid bias from omitted community-level factors that affect migration in evaluating the importance of specific household characteristics to the migration decision.

Table 5 presents the estimation results. In 1997, all regressors are statistically significant, with the exception of the last two distance categories in the county fixed effects model. The impact on the probability of migration is expressed as an odds ratio, i.e., a multiple of the probability given a unit change in the independent variable. For the specification with village fixed effects, an additional year of education increases the probability of migration by 1.021 times and an extra mu of land $(1 \mathrm{mu}$ equals 0.33 hectares),reduces migration probability by a factor of 0.940 . In addition, the number of laborers has a large positive effect, while children and household size have significant negative effects, on migration. With laborers and children included as regressors, the coefficient on household size should be interpreted as the effect of an additional household member who is not a laborer or a child, e.g., an elderly person. In 2001, all factors except the number of children and household size remain statistically significant. Comparing the magnitudes of the effects in 2001 to those in 1997, we find that the importance of education and land increases while that of labor, children, and household size decreases. Finally, the magnitudes of these effects tend to be somewhat smaller in the county fixed effects specification, but the relative importance and directions of change remain the same. 
From the additional variables included in the county fixed effects specification, we find that households in mountainous and hilly areas are 1.46 and 1.23 times more likely to migrate in 1997 than those living in flat areas. The measures of a household's distance from the market indicate a nonlinear relationship, which might be expected because remoteness has both positive and negative effects on migration. For example, households located closer to markets may have lower transportation costs making migration more likely or they may have more marketing outlets or offfarm opportunities nearby, both of which would reduce the likelihood of migration. In 1997, we find that, in areas 2 to 10 kilometers away from the market, people are more likely to migrate; however, beyond ten kilometers, the probability of migration is not influenced in a statistically significant way. Moreover, Table 5 indicates that the importance of these factors declines considerably from 1997 to 2001, which suggests that geography has a smaller influence on off-farm employment opportunities over time.

To estimate non-parametrically the relationship between the likelihood of migration and household endowments, we begin by regressing the log of household net income per capita on a set of exogenous endowments. These variables consist of the highest year of education, cultivated land per capita, household size, the share of household members that is laborers, the share of household members that is children, and village dummy variables that capture geographic and other community endowments that affect migration. Then, we estimate non-parametrically the relationship between the probability that the household has a migrant and its fitted log 
net income per capita. In this specification, fitted income acts as an index of exogenous household endowments in which each endowment is weighted by its relative importance to income generation. This approach reduces, but does not eliminate, the endogeneity problem caused by the effect of migration on income and the noise due to measurement error in incomes. Since migration is related positively to some endowments that increase income but related negatively to others, the direction of simultaneity bias is ambiguous. In the next section, with an instrument for migration we estimate, albeit roughly, each households income when the household does not have a migrant. When we examine the relationship between net income absent migration and the migration decision, the pattern of results is not altered in any important way.

The non-parametric results for 1997 and 2001 are depicted in Figure 1 and indicate that the relationship between migration probability and fitted log net income per capita is nonlinear. At low endowment levels, the likelihood of migration increases with endowments; however, at moderate levels of endowments, migration declines with endowments. ${ }^{8}$ The inflection point occurs at a value for fitted log income per capita of about 6.5 , which is just above the poverty line. ${ }^{9}$ Hence, households near the poverty line are most likely to migrate; however, for those having lower or higher income, the probability of migration is lower. This result suggests that a minimum level of productive resources is required for poor households to take advantage of new migration opportunities. McKenzie (2004) also find an inverted-Ushaped migration pattern. McKenzie attributes this result to binding credit constraints 
at low incomes and higher opportunity costs of migration at high incomes because greater wealth allows higher investment locally. The left side of the inverted-U is also consistent with a lack of labor or human capital in poor households. The right side is consistent with the finding of Zhao (1999), Guang and Lu (2005) and Knight and Song (2003) that the best-endowed households prefer local off-farm jobs so that they do not migrate.

In addition, Figure 1 indicates that, except for the richest households, the migration probabilities at any given endowment level increase from 1997 to 2001, which is consistent with overall trends. The increase in migration probability of the poorest households is substantial, going from 20 percent to about 27 percent. Over time, poor people are increasingly more likely to migrate than rich people, which is a trend that bodes well for the future potential role of migration in poverty reduction. Although these results suggest that household endowments have a strong influence on the decision to migrate by poor people, factors that impede migration may also be present. Liu (2005), Wang, (2004), Solinger (1999), Yang and Cai (2003) and Meng and Zhang (2001) emphasize the importance of policy barriers to migration associated with China's household registration system in addition to restrictive or discriminatory policies in urban areas.

To gain insight into perceived barriers to migration, we asked respondents what was the most important factor affecting migration decisions of men in the village, women in the village, and themselves personally in the 2000 CRPS. Table A4 in the Appendix reports the summary statistics. The four responses given by men that 
exceed 10 percent are agricultural labor demand (25.9 percent), lack of education or skills (25.3 percent), lack of information and social networks (18.3 percent), and inability to finance transportation and search costs (14.1 percent). For women, the responses exceeding 10 percent are unwillingness to be separated from children $(46.2$ percent), agricultural labor demand (21.0 percent), and lack of education or skills (12.7 percent). Overall, the respondents identify labor supply side factors. Notably, factors related to urban or local policies are perceived to have the least importance. Reports about own migration decisions are consistent with the reports for men and women in general. The important exception is that unwillingness to leave children is relatively more important in male self-reports and relatively less important in female self-reports. Subjective reports must be interpreted cautiously because they may reflect greater awareness of factors rather than their actual importance, e.g., labor demand conditions may be viewed as immutable. Nonetheless, the fact that policies restricting migration are not viewed as barriers by poor people themselves is an important finding.

The main result in this section is the inverted-U-shaped relationship between household endowments and migration probability, with the inflexion point slightly above the poverty line. Moreover, the levels of migration, especially for women, in our sample of poor counties are low relative to rural areas in other parts of China. Our analysis of the determinants of migration indicates that having adequate labor is a critical factor for facilitating migration and that the importance of human capital and land in the migration decision has increased over time. When asked about the 
importance of different barriers to migration, farmers in poor areas focus on factors affecting labor supply rather than on restrictive policies toward migrants. Taken together, these results indicate that the poorest households in China are not likely to supply migrants.

\section{Migration, Remittances, and Poverty}

To investigate how migration affects the welfare and poverty status of the migrant and family members, we focus on the immediate effect of migration on household income and remittances. ${ }^{10}$ Migrants generally earn higher incomes than they would if they had stayed on the farm. Using the CRPS 1997 data, Du (2001) found that off-farm wages are generally well above estimated marginal productivities of farm work. Yang (2004) makes a similar point by emphasizing the persistence of a surplus labor problem in China. If we add a dummy variable for migration to the income regressions with village fixed effects using the CPMS data, we find that, conditional on a household's resource endowments, households with migrants have per capita incomes that are 12 percent greater than those with no migrants and this percentage is relatively stable over time. Conducting a similar exercise using the CRPS data in 2000, we find that family income per capita increases by 77 percent if the family has a migrant. The association between migration and income is greater than in the CPMS data because all of the income of long-term migrants who are household heads, spouses, or unmarried children is included in family income, and because of differences in the sample counties. 
The main difficulty with regression-based estimates of the effect of migration on income is the likely endogeneity of the migration decision because of unobserved individual or community factors that also affect income. The panel nature of the CPMS allows us to eliminate the bias from time-invariant household heterogeneity by focusing on the effect of changes in migration on changes in income. Unfortunately, changes in migration status are not likely to be exogenous. To address the endogeneity problem directly, we use village migrant social networks as an identifying instrument for the migration decision following McKenzie (2004), deBrauw et al. (2002), deBrauw, Rozelle, and Taylor (1998), Taylor, Rozelle, and deBrauw (2003), Rozelle et al. (1999), and Zhao (2003). Past village migration is an attractive instrument because it is not influenced directly by unobserved household factors that affect both migration and incomes. However, village migration outcomes may reflect unobserved community factors that are positively or negatively correlated with incomes. For example, better roads facilitate migration but could also increase the returns to on-farm activities. In addition, poor land quality or weather variation may increase migration while reducing expected incomes. The size of village networks may influence the amount of remittances or gifts sent by the household's migrants or other friends and relatives independent of its effect on the migration decision itself. Thus, although the instrumental variables (IV) estimates are informative, they must be interpreted cautiously.

For panel data, an equation for household income can be written as follows: 


$$
y_{h v c t}=\beta_{1} X_{h v c t}+\beta_{2} M_{h v c t}+v_{c t}+u_{h v c}+e_{h v c t} \text {. }
$$

Subscripts h, v, c, and t index household, village, county, and year, respectively. In the equation, $\mathrm{y}$ is $\log$ income per capita, $\mathrm{X}$ is a vector of exogenous household characteristics, and $\mathrm{M}$ is a dummy variable indicating whether the household has a migrant. The other terms are county-year fixed effects, household fixed effects and unobserved household time-varying factors. In cross-sectional regressions, the last two terms comprise the error term.

The migration equation is:

$$
M_{h v c t}=\alpha_{1} X_{h v c t}+\alpha_{2} N_{v c t-1}+\lambda_{c t}+\mu_{h v c}+\varepsilon_{h v c t} .
$$

In equation (2), $\mathrm{N}$ is the share of villagers who migrated in the previous year, which is our measure of village migrant networks, and the remaining terms are county-year fixed effects, household fixed effects, and household time-varying errors and omissions. The variable $\mathrm{N}$ is constructed from information on other households in the same village so that it is not affected by the household's own migration decisions.

Using panel data enables us to difference out the household fixed effect. Moreover, some of the $\mathrm{X}$ variables do not change over time so that they drop out of the differenced equation. Because of concerns that changes in the remaining $\mathrm{X}$ variables may be endogenous to migration changes, we exclude them as well. We add initial characteristics that may be correlated with income growth or change in 
migration, including initial $\mathrm{X}$ values and initial migration status. The latter is related mechanically to changes in migration because previous migrant households cannot experience a positive change in migration and previous non-migrant households cannot experience a negative change in migration. In the change in migration equation, we include lagged village migrant network size in addition to the change in lagged village migrant network size. Hence, we have the following two equations for income growth and change in migration status:

$$
\begin{gathered}
\Delta y_{h v c t}=\beta_{1} \Delta M_{h v c t}+\beta_{2} M_{h v c t-1}+\beta_{3} X_{h v c t-1}+\Delta v_{c t}+\Delta e_{h v c t}, \quad \text { and } \\
\Delta M_{h v c t}=\alpha_{1} N_{v c t-1}+\alpha_{2} \Delta N_{v c t-1}+\alpha_{3} M_{h v c t-1}+\alpha_{4} X_{h v c t-1}+\Delta \lambda_{c t}+\Delta \varepsilon_{h v c t} .
\end{gathered}
$$

Equation (3) can be estimated using lagged village migrant networks and changes in lagged village migrant networks as the instruments. Equation (4) is the first stage regression. We control for county-time fixed effects by subtracting county-year means from all variables. All standard errors are adjusted for clustering at the village level. The estimation results for equations (1) to (4) are presented in Table 6. In estimating the level regressions described by equation (1), we pool the data from different years and find that migration increases income per capita by 9.6 percent using the OLS specification and by 8.5 percent using the IV specification. The first stage model is a linear probability model of household migration decisions. The results in column 5 of Table 6 indicate that lagged village migrant network size increases the likelihood of household migration significantly after controlling for 
covariates. Specifically, an additional migrant per household in the village last year increases the probability of household migration by 26.8 percent.

The results for the differenced income regressions in columns 3 and 4 of Table 6 indicate that migration increases household income per capita by 9.9 percent using OLS and by 13.1 percent using IV. The results for the first stage model in column 6 show that an additional migrant per household in the village last year increases the probability that the household's change in migration status will be positive by 14.8 percent. The effect of a lagged change in the village migrant network variable is negative 11 percent, which suggests that the size of village migrant networks two years earlier also has a positive effect on current migration changes. The high firststage F-statistics for both level and differenced regressions in Table 6 indicate that bias to coefficient and standard error estimates due to weak instruments is not a problem. Taken together, the regression results indicate that migration increases household income per capita from 8.5 to 13.1 percent, with the latter estimate being preferred if unobserved heterogeneity at the household level is the greatest source of potential bias.

If migration increases household income by 13.1 percent, we can measure its effect on the poverty headcount by a comparison of the actual poverty rate with that calculated for the counterfactual in which no households have migrants. This simulation ignores general equilibrium effects of large-scale migration changes on equilibrium wages in both urban and rural areas. Taking 2001 as the most recent year for which we have data and using China's official poverty line of 630 yuan in 2001, 
we find that the poverty headcount is 15.4 percent in the absence of migration compared to an actual poverty rate of 14.4 percent. The effect of migration on poverty reduction is not larger because only about one fifth of households that would be poor without migration actually have a migrant. If all the households in the sample had a migrant, the poverty rate would decline to 11.3 percent, again ignoring general equilibrium effects. Perhaps migration affects poor and non-poor households differently. We investigated the possibility of heterogeneous treatment effects by interacting the migration variable in the income equation with other household characteristics, including initial income or poverty status. ${ }^{11}$ However, we did not find any statistically significant interaction effects.

This analysis thus far has examined migration by household members and categorized migrant income as part of household income. However, the benefits of migration for family members remaining in rural villages depend upon the actual amount of remittances received from migrants, including long-term migrants. To investigate the remittance behavior of migrants, we use the CRPS data. ${ }^{12}$ Table 7 compares the incomes and income structure of both families and households with and without migrants. Families include key long-term migrants who are household heads, spouses of household heads, or unmarried children but households do not. Thus, family income includes all of the income of long-term migrants whereas household income includes only the remittances from such individuals. If a family has no longterm migrants, the family and the household units are the same. As Table 7 indicates, the income structure of families and households with migrants is dramatically 
different from those without migrants, as Taylor, Rozelle, and deBrauw (2003) also describe. Whereas agriculture accounts for more than two thirds of the income of non-migrant households, it represents only 26.2 percent of family income and 45.2 percent of household income in migrant households. The results in Table 7 also illustrate that standard household surveys, which do not include long-term migrants as household members, may underestimate the effect of migration on the average welfare of rural citizens because they overlook the income benefits to the migrant. Measured family income per capita is 12.5 percent greater than measured household income per capita for families having migrants.

Assuming that the income of long-term migrants is pooled fully with the income of other household members may overestimate the positive effects of migration on the welfare of other family members. Short-term and long-term migrants living far from home are unlikely to pool income fully with family members at home because they incur high costs of living where they reside. Thus, the effect of migration on the welfare of other family members depends on how much money the migrant actually decides to remit.

In table 8, we compare the incomes of migrants, including short-term migrants, and other family members before and after remittances to illustrate how remittances affect the income and poverty of both groups. Before remittances, the mean income of migrants is 2907 yuan, while the mean income of other family members is 602 yuan per person. Migrants remitted a third of their income on average, 980 yuan, with other family members receiving 465 yuan per person, which constitutes 77 percent of 
their own earned income. Using the rural poverty line of 635 yuan in 2000, we calculate that the poverty incidence of migrants was 17.5 percent before remittances and 27.8 percent after remittances. At the same time, the poverty rate of other family members was 67.1 percent before receiving remittances and 49.2 percent afterward. Using a higher urban poverty line to measure the poverty of migrants increases the poverty rate, bringing the poverty rates of migrants and other family members closer to each other. These calculations take migration income and remittances as exogenous to the income of other family members. However, other household members may respond to receiving remittances by reducing labor supply or, alternatively, they may become more productive if remittances finance health expenditures or other productive investments. Thus, the calculated effects of remittances on the poverty status of other household members may be either overstated or understated.

To assess how well remittances respond to the needs of other family members, we describe the remittance decisions of migrants from households with different endowment levels as well as other outcomes of interest in Table 9. Using fitted log income to index household endowments, we find that the share of income remitted by migrants is much higher for families in the lowest endowment decile, even though income is substantially lower for these migrants. In families with above-average endowments, the remittance share of income is about 43 percent with no significant difference for families in the top endowment decile. In general, higher-endowment families have higher migrant income per migrant, a larger number of migrants, more remittances per non-migrant member, and higher household income per capita. To 
analyze the determinants of remittance decisions more systematically in a multivariate framework, we estimate OLS regressions in which the dependent variables are the log of migrant remittances and the share of migrant income remitted. The unit of observation is the individual migrant. Our objective is to describe the extent to which remittance decisions respond positively to the needs of poorer family members.

To focus on the redistributive aspects of remittance decisions, we include as regressors only the log of the migrant income and a weighted family endowment measure, namely, fitted log family income per capita. This equation can be interpreted as a reduced form relationship between the incomes of migrants and family endowments. ${ }^{13}$ We estimate each specification with and without village fixed effects. For the remittance share equations, we also estimate specifications that account for truncation between zero and one in the dependent variable, i.e., a Tobit model, and that account for selection effects associated with the migration decision. ${ }^{14}$ The results are reported in Table 10. The log remittance regressions indicate that 50 to 55 percent of marginal migrant income is remitted to other family members and no statistically significant relationship exists between remittance amounts and the income level of other household members.

The results of the remittance share equations in the first column of Table 10 indicate that, as migrant incomes increase by one percent, the share of income remitted decreases by 0.050 to 0.077 percentage points, ceteris paribus. Hence, this relationship is not income-equalizing. However, the results in column 3 of Table 10 show that remittance shares increase when family endowments are low and that this 
relationship is statistically significant. A one percentage decrease in predicted family income per capita increases the remittance share by 0.058 to 0.089 percentage points. Thus, migrants from poor families remit more of their income, when migrant income levels are held constant. Moreover, controlling for selection bias reduces the magnitude of this effect by about 10 percent. If one assumes that the village fixed effects specification provides more reliable estimates by controlling for omitted community factors that affect remittances, the preferred estimate of the coefficient on fitted family income per capita is about 0.079 , which is based on the Tobit results and a 10 percent correction for selectivity. In general, we find evidence that remittances respond to the needs of other household members, but the magnitude of the responsiveness is not particularly large. Based on the reported point estimate, a 100 percent increase in family income per capita reduces the remittance share by only 8 percentage points. However, migrants do remit a large share of their income so that the effect on measured poverty rates may be considerable.

In summary, in this section our main empirical finding is that having a migrant increases household income per capita by between 8.5 and 13.1 percent. We do not find any empirical support for the proposition that income effects are lower or higher for poor households. Based on simulations, we find that migration reduces the poverty headcount ratio by only 1.1 percentage points, mainly because so few of poor households have migrants. Among those that do, remittances to family members remaining in rural areas are substantial and have a considerable effect on calculated 
poverty rates. Finally, remittance shares are somewhat responsive to the needs of other family members.

\section{Conclusion}

In this paper, we analyze two complementary household data sets from China's poor areas to provide empirical evidence on the role of migration in poverty alleviation. On the positive side, we find that structural change in China has involved labor from western China increasingly beginning in the late 1990s. The likelihood that low-endowment households have migrants has increased over time, while the importance of local geography in the migration decision has declined. Households near the poverty line are more likely to have a migrant than richer or poorer households. Hence, for some households, migration opportunities play an important role in escaping poverty. Urban policy, e.g., hukou restrictions, is not perceived to have erected significant barriers to migration by poor households. Importantly, migration increases household income per capita by between 8.5 and 13.1 percent and migrant remittances are both significant and responsive to the needs of household members.

On the negative side, the overall impact of migration on the poverty headcount has been modest, mainly because most poor households do not have migrants. The poorest rural households with few laborers and poor human capital are unable to allow members to migrate. Even if all households had migrants, we find that many of them would remain poor. Thus, migration will not solve China's poverty problems by 
itself any time soon. Nonetheless, including poor households in the ongoing process of structural change may still merit high priority in policy making in China since industrialization and growth of the service sector will continue to be the engines of growth and employment for the foreseeable future. 


\section{Acknowledgement}

The authors thank the Ford Foundation for field research support and for funding Yang Du's visit to the University of Michigan; they are grateful to Lian Jin and Guofang Huang for able research assistance.

\section{Footnotes}

1. Chan (2001), deBrauw et al. (2002), Johnson (2003), Liang and White (1996), Liang (2001), and Liang and Ma (2004) provide overviews of migration trends in China.

2. In 1997, the CRPS sample is identical to the NBS rural household survey in the 6 counties surveyed. Mean household size is 4.7 using the NBS definition and 4.2 using a strict 6-month residence standard.

3. In 1997, 10 households were sampled in each village and the number of villages ranges from 6 to 10 across the four counties.

4. In the 1997 CRPS, the mean number of household members based on a strict 6month standard is 4.2 , compared to 4.6 according to the NBS definition, which includes other family members whose economic life is tied closely to the household.

5. Chinese employment statistics divide workers into three large sectors, namely primary (agriculture), secondary (industry and construction), and tertiary (mainly trade and services). We define the non-agricultural sector to include the secondary and tertiary sectors. 
6. The wages of these migrants are represented to some degree in remittance data. However, in 2002, remittances were less than 5 percent of rural income in all regions.

7. Two provinces in the southwest, Guizhou and Yunnan, are exceptions as they experience substantial increases in migration.

8. At higher levels of income not indicated in Figure 1, the migration probability increases with income once again.

9. In 1997, the poverty line was 640 yuan, which yields log income per capita equal to 6.46 .

10. Giles (forthcoming), deBrauw, Rozelle, and Taylor (1999), Taylor, deBrauw, and Rozelle ( 2004), Murphy ( 2004) and Zhao ( 2002) examine other dimensions of the effects of migration that are beyond the scope of this paper. For example, the departure of the migrant could increase the per-capita endowment of remaining family members, which would increase labor productivity on the farm. The migrant could provide information or other social insurance assistance to the family. Migration could diversify the household income portfolio. Remittances could help finance new household investments and return migrants could invest in new projects upon their return to the village. In addition, migration could affect other families in the village by providing information on employment opportunities outside the village and increasing the availability of funds for borrowing. Some of these effects are captured indirectly in our reduced form estimates of the impact of migration on household incomes. 
11. However, adding initial income variables introduces an additional endogeneity problem due to lagged dependent variables.

12. Given the definition of household membership in the CPMS, household income includes all of the income of long-term migrants defined as household members and only remittances of long-term migrants who are not household members.

13. We also tried using the log of household income per capita, excluding the migrants income, but the effects were insignificant perhaps due to high measurement error.

14. The identifying variables in the selection equation are the same as those used previously. 


\section{References}

Cai, Fang, Park, Albert, Zhao, Yaohui, 2005. The Chinese labor market in the reform era. Working paper.

Chan, Kam W., 2001. Recent migration in China: patterns, trends, and policies. Asian Perspectives 25, 127-155.

Chen, Shaohua, Ravallion, Martin, 2004. China's (Uneven) Progress Against Poverty, World Bank Policy Research Working Paper No. 3408.

deBrauw, Alan, 2004. Are women taking over the farm in China? Working paper. deBrauw, Alan, Rozelle, Scott, Taylor, Edward, 1999. Migration, remittances, and agricultural productivity in China. American Economic Review 89, 400-418.

deBrauw, Alan, Huang, Jikun, Rozelle, Scott, Zhang, Linxiu, and Zhang, Yigang, 2002. The evolution of China's rural labor markets during the reforms. Journal of Comparative Economics 30, 329-353.

Du, Yang, 2001. Labor Supply in China's Poor Areas [pinkun diqu nonghu laodong gongji yanjiu]. Huawen Press, Beijing.

Giles, John, forthcoming. Is life more risky in the open?: household risk-coping and the opening of China's labor markets. Journal of Development Economics.

Guang, Lei, Zheng, Lu, 2005. Migration as the second-best option: local power and off-farm employment. The China Quarterly 181, 22-45.

Johnson, D. Gale, 2003. Provincial migration in China in the 1990s. China Economic Review 14, 22-31. 
Knight, John, Song, Lina, 2003. Chinese peasant choices: migration, rural industry or farming. Oxford Development Studies 31, 123-147.

Liang, Zai, White, Michael J., 1996. Internal migration in China, 1950-1988. Demography 33, 375-384.

Liang, Zai, 2001. The age of migration in China. Population and Development Review 27, 499-524.

Liang, Zai, Ma, Zhongdong, 2004. China's floating population: new evidence from the 2000 census. Population and Development Review 30, 467-488.

Liu, Zhiqiang, 2005. Institution and inequality: the hukou system in China, Journal of Comparative Economics 33: 133-157.

McKenzie, David, Rapoport, Hillel, 2004. Network effects and the dynamics of migration and inequality: theory and evidence from Mexico. BREAD Working Paper No. 063.

Meade, Robert, Rawski, Thomas, 1998. In search of China's phantom farmers. World Development 26, 767-781.

Meng, Xin, Zhang, Junsen, 2001. The two-tier labor market in urban China: occupational segregation and wage differentials between urban residents and rural migrants in Shanghai. Journal of Comparative Economics 29, 485-504.

Murphy, Rachel, 2000. Return migrant entrepreneurs and economic diversification in two counties in south Jiangxi, China: erratum,” Journal of International Development 12(2): 297. 
Park, Albert, Wang, Sangui, 2001. China's poverty statistics. China Economic Review 12, 384-398.

Rozelle, Scott, Li, Guo, Shen, Minggao, Hughart, Amelia, Giles, John, 1999. Leaving China's farms: survey results of new paths and remaining hurdles to rural migration. The China Quarterly 158, 367-393.

Solinger, Dorothy, 1999. Contesting Citizenship in Urban China: Peasant Migrants, the State, and the Logic of the Market. University of California Press, Berkeley.

Taylor, J. Edward, Rozelle, Scott, de Brauw, Alan, 2003. Migration and incomes in source communities: a new economics of migration perspective from China. Economic Development and Cultural Change 52, 75-102.

Wang, Fei-Ling, 2004. Reformed migration control and new targeted people: China's hukou system in the 2000s. The China Quarterly 177, 115-132.

The World Bank, 1997. Sharing Rising Incomes: Disparities in China. The World Bank, Washington, D.C.

The World Bank, 2001. China: Overcoming Rural Poverty. The World Bank, Washington, D.C.

Yang, Dennis T., 2004. Education and allocative efficiency: household income growth during rural reforms in China. Journal of Development Economics 74, 137-162.

Yang, Dennis T., Cai, Fang, 2003. The political economy of China's rural-urban divide. In: Hope, Nick, Yang, Dennis T., Yang, Mu (eds.), How Far Across 
the River?: Chinese Policy Reform at the Millennium, Stanford University Press, Stanford, pp. 389-416.

Zhang, Linxiu, de Brauw, Alan, Rozelle, Scott, 2004. China's rural labor market development and its gender implications. China Economic Review 15, 230247.

Zhang, Linxiu, Huang, Jikun, Rozelle, Scott, 2002. Employment, emerging labor markets, and the role of education in rural China. China Economic Review 13, 313-328.

Zhao, Yaohui, 1999. Migration and earnings differences: the case of rural China, Economic Development and Cultural Change 47, 767-782.

Zhao, Yaohui, 2002. Causes and consequences of return migration: recent evidence from China. Journal of Comparative Economics 30, 376-394.

Zhao, Yaohui, 2003. The role of migrant networks in labor migration: the case of China. Contemporary Economic Policy 21, 500-511. 
Figure 1

Probability that Households have Migrants

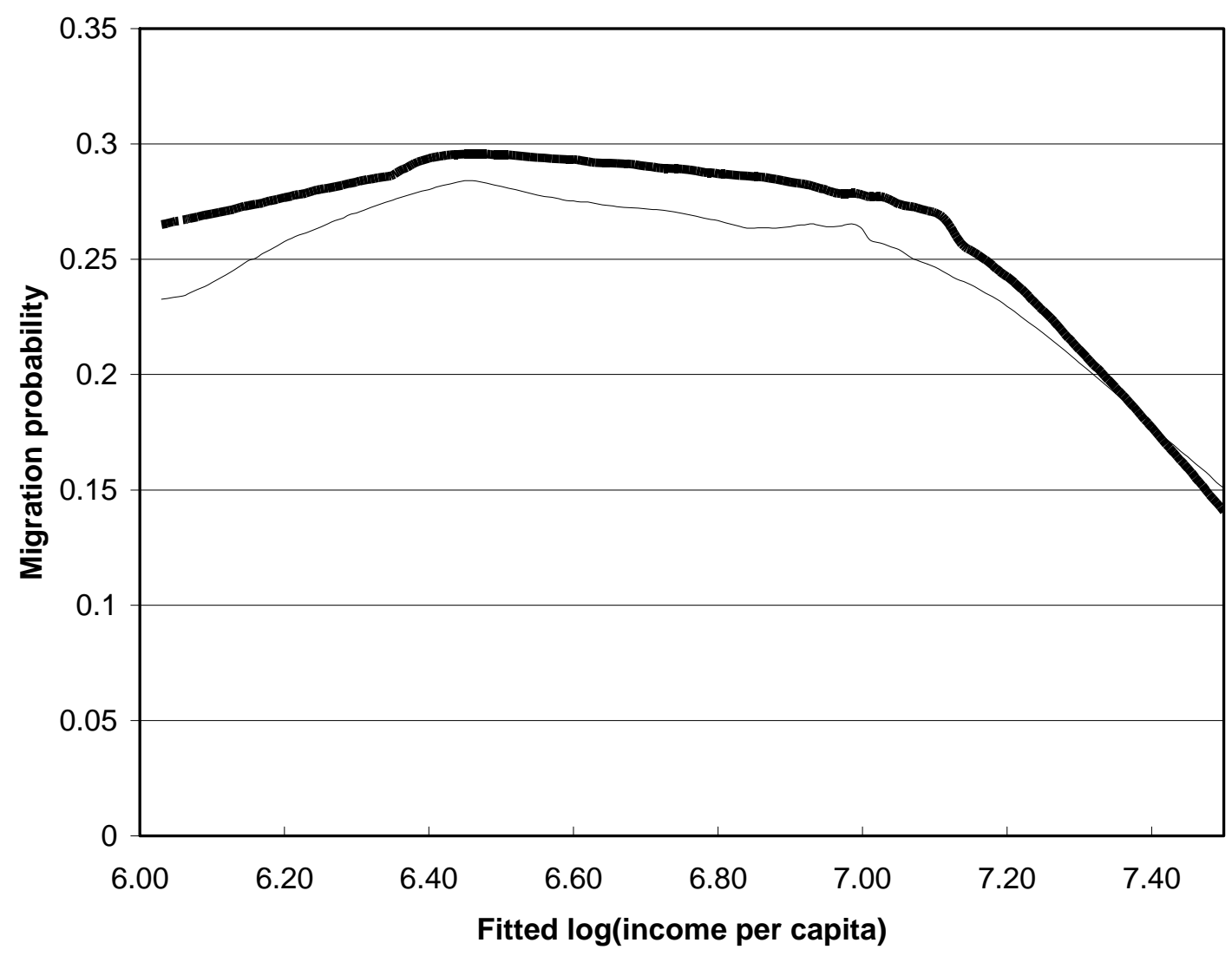


Legend to Figure 1 
Table 1

Percentage of Employed Persons Working Primarily in Agriculture

\begin{tabular}{lccccc}
\hline Region & 1993 & 1995 & 1997 & 2000 & 2002 \\
\hline East & 45.79 & 42.13 & 42.16 & 45.51 & 39.17 \\
Center & 60.27 & 56.04 & 54.12 & 56.30 & 55.00 \\
Northeast & 38.04 & 36.48 & 37.68 & 44.92 & 44.44 \\
Southwest & 70.75 & 67.50 & 67.46 & 63.58 & 61.58 \\
Northwest & 60.86 & 58.74 & 58.00 & 57.60 & 55.91 \\
\hline
\end{tabular}

Source: Statistical Yearbook of China, various years 
Table 2

Percentage of Rural Household Income from Wages

\begin{tabular}{llllll}
\hline Region & 1993 & 1995 & 1997 & 2000 & 2002 \\
\hline East & 29.48 & 30.77 & 30.68 & 33.84 & 44.46 \\
Center & 17.87 & 18.72 & 18.70 & 22.61 & 33.11 \\
Northeast & 16.15 & 16.47 & 16.57 & 19.15 & 25.54 \\
Southwest & 13.29 & 15.42 & 13.27 & 17.49 & 30.85 \\
Northwest & 14.16 & 14.00 & 13.98 & 18.25 & 27.12 \\
\hline
\end{tabular}

Source: National Bureau of Statistics rural household surveys, reported in Statistical Yearbook of China, various years. 
Table 3

Long-term Migration from 2000 Census

\begin{tabular}{lcccc}
\hline Region & Migration rate & $\begin{array}{c}\text { To another } \\
\text { township in same } \\
\text { county }\end{array}$ & $\begin{array}{c}\text { To another } \\
\text { county in same } \\
\text { province }\end{array}$ & $\begin{array}{c}\text { To another } \\
\text { province }\end{array}$ \\
\hline National & 8.49 & 2.61 & 2.46 & 3.42 \\
East & 8.62 & 3.24 & 3.80 & 1.58 \\
Central & 8.34 & 2.28 & 1.66 & 4.40 \\
Northeast & 9.44 & 3.70 & 3.65 & 2.09 \\
Southwest & 9.33 & 2.24 & 2.08 & 5.01 \\
Northwest & 5.72 & 2.19 & 1.79 & 1.74 \\
\hline
\end{tabular}

Notes:

(i) The 2000 census interviews only individuals who have lived at their current place of residence for at least 6 months.

(ii) Long-term migration rates are the percent of those holding hukou from each region who have lived in a township different than that fro which they have hukou. 
Table 4

Percent of Rural Households in Poor Counties Having at least one Migrant

\begin{tabular}{lccccc}
\hline Province/Region & 1997 & 1998 & 1999 & 2000 & 2001 \\
\hline Chongqing & 36.33 & 36.92 & 31.83 & 35.25 & 35.17 \\
Sichuan & 28.60 & 28.37 & 30.92 & 26.30 & 27.78 \\
Guizhou & 17.35 & 22.57 & 18.74 & 22.81 & 24.04 \\
Yunnan & 8.85 & 12.70 & 10.23 & 13.53 & 11.82 \\
Guangxi & 33.28 & 33.21 & 36.38 & 34.98 & 33.58 \\
Southwest & $\mathbf{2 1 . 7 4}$ & $\mathbf{2 2 . 0 5}$ & $\mathbf{2 1 . 4 3}$ & $\mathbf{2 2 . 4 9}$ & $\mathbf{2 2 . 1 9}$ \\
Shanxi & 15.44 & 23.20 & 30.78 & 30.16 & 36.18 \\
Gansu & 29.12 & 37.16 & 37.28 & 37.96 & 37.52 \\
Qinghai & 17.68 & 20.18 & 23.21 & 20.36 & 23.39 \\
Ningxia & 26.58 & 48.68 & 51.84 & 49.08 & 54.61 \\
Xinjiang & 6.96 & 2.16 & 2.96 & 3.52 & 3.60 \\
Northwest & $\mathbf{1 8 . 8 1}$ & $\mathbf{2 6 . 4 2}$ & $\mathbf{2 9 . 9 5}$ & $\mathbf{2 9 . 5 6}$ & $\mathbf{3 2 . 4 4}$ \\
All & $\mathbf{2 3 . 0 3}$ & $\mathbf{2 5 . 1 6}$ & $\mathbf{2 5 . 0 7}$ & $\mathbf{2 6 . 1 1}$ & $\mathbf{2 6 . 4 4}$ \\
\hline
\end{tabular}

Source: China Poverty Monitoring Survey data from all 592 national poor counties. 
Table 5

Determinants of Household Migration

\begin{tabular}{lcccccc}
\hline & & 1997 & & & 2001 & \\
& $\begin{array}{r}\text { Odds } \\
\text { Ratio }^{\mathrm{a}}\end{array}$ & Std. Err. & $\mathrm{P}>|\mathrm{z}|$ & $\begin{array}{r}\text { Odds } \\
\text { Ratio }^{\mathrm{a}}\end{array}$ & Std. Err. & $\mathrm{P}>|\mathrm{z}|$ \\
\hline Village fixed effects & & & & & & \\
& & & & & & \\
Highest years of educ & 1.021 & 0.00613 & 0.001 & 1.032 & 0.00604 & 0.000 \\
Cultivated land p.c. (mu) & 0.940 & 0.0109 & 0.000 & 0.930 & 0.0143 & 0.000 \\
Laborers & 2.307 & 0.0519 & 0.000 & 2.069 & 0.0511 & 0.000 \\
Children & 0.937 & 0.0167 & 0.000 & 0.977 & 0.0209 & 0.279 \\
Household size & 0.931 & 0.0163 & 0.000 & 0.974 & 0.0195 & 0.191 \\
$\mathrm{~N}^{\mathrm{b}}$ & & 27,971 & & & 30,107 & \\
\hline & & & & & & \\
County fixed effects & & & & & & \\
& & & & & & \\
Highest years of educ & 1.014 & 0.00482 & 0.002 & 1.025 & 0.00474 & 0.000 \\
Cultivated land p.c. (mu) & 0.953 & 0.00761 & 0.000 & 0.944 & 0.00897 & 0.000 \\
Laborers & 1.883 & 0.0329 & 0.000 & 1.743 & 0.0341 & 0.000 \\
Children & 0.947 & 0.0138 & 0.000 & 0.949 & 0.0168 & 0.003 \\
Household size & 0.938 & 0.0132 & 0.000 & 1.008 & 0.0163 & 0.612 \\
Hilly (0/1) & 1.230 & 0.0868 & 0.003 & 1.110 & 0.0718 & 0.107 \\
Mountainous (0/1) & 1.462 & 0.1060 & 0.000 & 1.264 & 0.0829 & 0.000 \\
2-5 km from market & 1.158 & 0.0394 & 0.000 & 1.118 & 0.0353 & 0.000 \\
5-10 km from market & 1.144 & 0.0489 & 0.002 & 1.019 & 0.0404 & 0.641 \\
10-20km from market & 0.896 & 0.0700 & 0.159 & 1.063 & 0.0583 & 0.269 \\
$>$ 20km from market & 1.067 & 0.0595 & 0.247 & 1.038 & 0.0744 & 0.602 \\
$\mathrm{~N}^{\mathrm{b}}$ & & 40,680 & & & 43,848 & \\
\hline & & & & & &
\end{tabular}

Notes

(i) The odds ratio is a multiple of the probability of migration given a unit change in the independent variable.

(ii) Data from communities having no variation in whether or not households have migrants are dropped automatically. 
Table 6: The Effect of Migration on Household Income Per Capita

\begin{tabular}{|c|c|c|c|c|c|c|c|c|c|c|c|c|}
\hline \multirow{4}{*}{$\begin{array}{l}\text { Dependent variable } \\
\text { Model } \\
\text { Household has migrant }(1 / 0)\end{array}$} & \multicolumn{4}{|c|}{ Log(household income p.c.) } & \multicolumn{4}{|c|}{$\Delta \log (\text { household income p.c. })^{\mathrm{a}}$} & \multirow{2}{*}{\multicolumn{2}{|c|}{$\begin{array}{l}\text { Has migrant? } \\
\text { (5) OLS }\end{array}$}} & \multirow{2}{*}{\multicolumn{2}{|c|}{$\begin{array}{l}\Delta \text { has migrant? } \\
\text { (6) OLS }\end{array}$}} \\
\hline & \multicolumn{2}{|c|}{ (1) OLS } & \multicolumn{2}{|c|}{ (2) IV } & \multicolumn{2}{|c|}{ (3) OLS } & \multicolumn{2}{|c|}{ (4) IV } & & & & \\
\hline & Coef. & Std. Err. & Coef. & Std. Err. & Coef. & Std. Err. & Coef. & Std. Err. & Coef. $S$ & Std. Err. & Coef. & Std. Err. \\
\hline & 0.0960 & 0.00444 & 0.0847 & 0.0302 & & & & & & & & \\
\hline$\Delta$ household has migrant & & & & & 0.0986 & 0.00579 & 0.131 & 0.0523 & & & & \\
\hline $\begin{array}{l}\text { Village migrants per household } \\
\text { (lag) }\end{array}$ & & & & & & & & & 0.268 & 0.00751 & 0.148 & 0.00697 \\
\hline $\begin{array}{l}\Delta \text { village migrants per household } \\
\text { (lag) }\end{array}$ & & & & & & & & & & & -0.110 & 0.00753 \\
\hline Household has migrant (lag) & & & & & 0.0195 & 0.00428 & 0.0374 & 0.0298 & & & -0.583 & 0.00510 \\
\hline Highest yrs of schooling & 0.0149 & 0.000637 & 0.0149 & 0.000638 & 0.00148 & 0.000556 & 0.00142 & 0.000571 & 0.00183 & 0.000417 & 0.00199 & 0.000363 \\
\hline Cultivated land p.c. (mu) & 0.0169 & 0.00205 & 0.0169 & 0.00205 & 0.00221 & 0.00132 & 0.00233 & 0.00134 & -0.00366 & 0.000784 & -0.00279 & 0.000639 \\
\hline Household size & -0.106 & 0.00153 & -0.106 & 0.00201 & -0.0376 & 0.00128 & -0.0385 & 0.00195 & 0.0444 & 0.00114 & 0.0307 & 0.000954 \\
\hline Labor/household & 0.194 & 0.0115 & 0.197 & 0.0150 & 0.0588 & 0.00976 & 0.0519 & 0.0147 & 0.332 & 0.00825 & 0.221 & 0.00709 \\
\hline Childre & 0.0667 & 00956 & 0.0658 & 0.00970 & 0.0498 & 0.00822 & 0.0513 & 0.00854 & -0.0711 & 0.00684 & -0.0440 & 0.00578 \\
\hline Hilly area (1/0) & -0.0928 & 0.0152 & -0.0925 & 0.0152 & -0.0272 & 0.0112 & -0.0277 & 0.0112 & 0.0167 & 0.00812 & 0.0134 & 0.00747 \\
\hline Mountainous area (1/0) & -0.168 & 0.0156 & -0.168 & 0.0156 & -0.0228 & 0.0107 & -0.0236 & 0.0108 & 0.0258 & 0.00799 & 0.0211 & 0.00740 \\
\hline Distance to market $2-5 \mathrm{~km}$ & 0.000458 & 0.00700 & 0.000596 & 0.00702 & -0.00241 & 0.00532 & -0.00268 & 0.00533 & 0.00771 & 0.00398 & 0.00600 & 0.00358 \\
\hline Distance to market $5-10 \mathrm{~km}$ & -0.0106 & 0.00875 & -0.0105 & 0.00876 & -0.000726 & 0.00651 & -0.000774 & 0.00651 & 0.000536 & 0.00460 & -0.000747 & 0.00424 \\
\hline Distance to market $10-20 \mathrm{~km}$ & -0.0250 & 0.0120 & -0.0250 & 0.0119 & -0.0101 & 0.00938 & -0.0102 & 0.00940 & -0.00193 & 0.00626 & 0.00302 & 0.00577 \\
\hline Distance to market $>20 \mathrm{~km}$ & -0.0407 & 0.0152 & -0.0409 & 0.0152 & -0.0157 & 0.0129 & -0.0156 & 0.0129 & -0.00824 & 0.00779 & -0.00228 & 0.00801 \\
\hline Revolutionary base area & 0.0334 & 0.0196 & 0.0336 & 0.0196 & 0.0275 & 0.0208 & 0.0273 & 0.0208 & 0.00988 & 0.0101 & 0.00687 & 0.0106 \\
\hline Minority area & -0.0151 & 0.0130 & -0.0154 & 0.0131 & 0.0157 & 0.0104 & 0.0163 & 0.0105 & -0.0208 & 0.00676 & -0.0162 & 0.00653 \\
\hline Constant & 0.000080 & 0.00278 & 0.000083 & 0.00278 & 0.000030 & 0.00171 & 0.000024 & 0.00171 & 0.000000 & 0.00147 & 0.000000 & 0.00126 \\
\hline $\mathrm{N}$ & 196 & 928 & 196 & 928 & 147,3 & 345 & 147 & 345 & 196, & 928 & 147 & 345 \\
\hline F-stat for instruments & & & & & & & & & 1,27 & 75.4 & 247 & \\
\hline
\end{tabular}

Notes 
(i) The estimates are based on CPMS data from 1997 to 2001.

(ii) All specifications include county-year fixed effects.

(iii) All standard errors are corrected for village clustering.

(iv) In differenced regressions, unless specified variables are initial period values. 
Table 7

Income Comparison of Families and Households

\begin{tabular}{lcc}
\hline & With migrants & Without migrants \\
\hline Family income per capita & 1,200 & 698 \\
& 318 & 494 \\
Agricultural income & 81 & 204 \\
Local off-farm income & 802 & -- \\
Migration income & & \\
& 1,067 & 698 \\
Household income per capita & & 494 \\
& 482 & 204 \\
Agricultural Income & 121 & -- \\
Local off-farm income & 465 & \\
Migration/remittance income & & \\
\hline
\end{tabular}

Notes

(i) The family unit includes household members plus all spouses and unmarried children of household members, regardless of the location of their residence.

(ii) Households include individuals who lived at home for at least six months in the past year. 
Table 8

Incomes of Migrants and Other Family Members, 2000

Migrants Other family members

\section{Income}

Income per capita before remittance

$2907 \quad 602$

Remittances per capita

$-980$

465

Income per capita after remittance

1928

1067

Poverty incidence (rural poverty line)

Poverty incidence before remittance

$17.5 \%$

$67.1 \%$

Poverty incidence after remittance

$27.8 \%$

$49.2 \%$

Poverty incidence (lowest city poverty line)

Poverty incidence before remittance

$25.1 \%$

$37.3 \%$

Poverty incidence after remittance

$37.3 \%$

Note: In 2000, the lowest city poverty line is 143 yuan per month 
Table 9

Remittances, Migration, and Family Endowments, 2000

\begin{tabular}{|c|c|c|c|c|}
\hline $\begin{array}{c}\text { Percentile of fitted log family income } \\
\text { per capita }\end{array}$ & $0-10 \%$ & $10-50 \%$ & $50-90 \%$ & $90-100 \%$ \\
\hline Remittances/migrant income & 0.621 & 0.481 & 0.425 & 0.434 \\
\hline Migrant income per migrant & 1,583 & 2,121 & 2,882 & 4,162 \\
\hline Number of migrants (persons) & 1.11 & 1.26 & 1.42 & 1.39 \\
\hline $\begin{array}{l}\text { Remittances per household member } \\
\text { (yuan) }\end{array}$ & 269 & 272 & 496 & 958 \\
\hline Household income per capita (yuan) & 78.6 & 296 & 430 & 777 \\
\hline $\mathrm{N}$ & 18 & 103 & 130 & 38 \\
\hline
\end{tabular}


Table 10

Determinants of Migrant Remittances, 2000

\begin{tabular}{|c|c|c|c|c|c|c|c|}
\hline Independent variables & $\begin{array}{c}\text { Ln(migrant } \\
\text { income) } \\
\text { Coef. }\end{array}$ & Std.Err. & $\begin{array}{l}\text { Fitted } \ln (\text { family } \\
\text { income per } \\
\text { capita) } \\
\text { Coef. }\end{array}$ & Std.Err. & Specification & $\begin{array}{l}\text { Village } \\
\text { fixed } \\
\text { effects }\end{array}$ & $\mathrm{N}$ \\
\hline Log remittances & $0.546 * * *$ & 0.0556 & -0.315 & 0.268 & OLS & & 362 \\
\hline Log remittances & $0.500 * * *$ & 0.0570 & -0.218 & 0.424 & OLS & $X$ & 362 \\
\hline Remittances/migrant income & $-0.0527 * * *$ & 0.0112 & $-0.0632 * *$ & 0.0286 & OLS & & 312 \\
\hline Remittances/migrant income & $-0.0542 * * *$ & 0.0112 & $-0.0784 *$ & 0.0455 & OLS & $\mathrm{X}$ & 312 \\
\hline Remittances/migrant income & $-0.0765 * * *$ & 0.0135 & $-0.0634 * *$ & 0.0307 & Tobit & & 312 \\
\hline Remittances/migrant income & $-0.0747 * * *$ & 0.0128 & $-0.0886^{*}$ & 0.0459 & Tobit & $X$ & 312 \\
\hline Remittances/migrant income & $-0.0504 * * *$ & 0.0112 & $-0.0575 * *$ & 0.0294 & Heckman & & 312 \\
\hline Remittances/migrant income & $-0.0542 * * *$ & 0.0104 & -0.0702 & 0.0458 & Heckman & $X$ & 312 \\
\hline
\end{tabular}

Note: The Tobit model specifications in rows 5 and 6 account for truncation between zero and one. The Heckman model specifications in rows 7 and 8 account for selection of who migrates. 


\section{Appendix}

Table A1

Number of Poor Counties in 2001

\begin{tabular}{|c|c|c|c|c|c|}
\hline Region & Province & $\begin{array}{l}\text { Number of } \\
\text { poor } \\
\text { counties }\end{array}$ & Region & Province & $\begin{array}{l}\text { Number of } \\
\text { poor } \\
\text { counties }\end{array}$ \\
\hline \multirow[t]{10}{*}{ East } & Beijing & 0 & \multirow[t]{4}{*}{ Northeast } & Liaoning & 9 \\
\hline & Tianjin & 0 & & Jilin & 5 \\
\hline & Shanghai & 0 & & Helongjiang & 11 \\
\hline & Jiangsu & 0 & & Total & 25 \\
\hline & Zhejiang & 0 & \multirow[t]{6}{*}{ Southwest } & Chongqing & 10 \\
\hline & Fujian & 8 & & Sichuan & 17 \\
\hline & Shandong & 10 & & Guizhou & 43 \\
\hline & Guangdong & 0 & & Yunnan & 66 \\
\hline & Hainan & 5 & & Xizang & 0 \\
\hline & Total & 23 & & Guangxi & 28 \\
\hline \multirow[t]{9}{*}{ Central } & Hebei & 37 & \multirow{9}{*}{ Northwest } & Total & 164 \\
\hline & Shanxi & 35 & & Shanxi & 43 \\
\hline & Neimenggu & 29 & & Gansu & 40 \\
\hline & Anhui & 12 & & Qinghai & 14 \\
\hline & Jiangxi & 18 & & Ningxia & 8 \\
\hline & Henna & 28 & & Xinjiang & 24 \\
\hline & Hubei & 25 & & Total & 129 \\
\hline & Hunan & 7 & & & \\
\hline & Total & 191 & & $\begin{array}{l}\text { National } \\
\text { total }\end{array}$ & 532 \\
\hline
\end{tabular}


Table A2

Summary Statistics

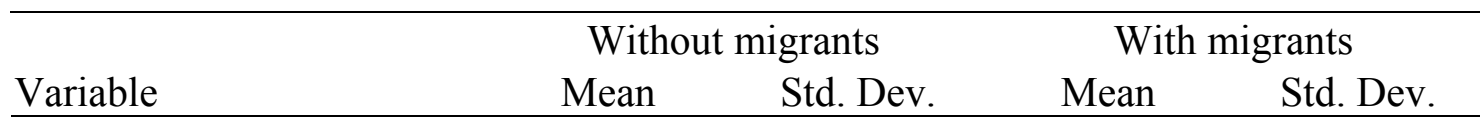

China Poverty Monitoring Survey, 1997 to 2001

Log income per capita

Highest years of educ

Cultivated land p.c. (mu)

Household size

Laborers

Children ( $<16$ years)

Hilly $(0 / 1)$

Mountainous (0/1)

2-5 $\mathrm{km}$ from market

$5-10 \mathrm{~km}$ from market

$10-20 \mathrm{~km}$ from market

$>20 \mathrm{~km}$ from market

Revolutionary base area

Minority region

$\mathrm{N}$
1368

7.59

2.39

4.38

2.46

1.11

0.216

0.606

0.346

0.194

0.0913

0.0733

0.124

0.358

180,984
959

3.33

3.56

1.41

1.03

1.07

0.411

0.489

0.476

0.395

0.288

0.261

0.330

0.479
1531

8.35

1.65

4.71

2.97

0.940

0.242

0.607

0.398

0.189

0.0695

0.0500

0.109

0.263

61,746
954

2.81

2.25

1.39

1.12

1.00

0.429

0.489

0.490

0.392

0.254

0.218

0.312

0.440

China Rural Poverty Survey, 2000

Income per capita

Highest years of educ

Cultivated land p.c. (mu)

Household size

Laborers/household size

Children/household size

$\mathrm{N}$
702

6.44

1.75

4.11

0.559

0.304

280
825

3.64

1.77

1.31

0.249

0.219
1203

8.09

1.59

4.69

0.628

0.290

289
981

2.98

1.59

1.26

0.223

0.206

Note: The CPMS sample statistics pool all household data from 1997 to 2001 
Table A3

Migration Frequency

\begin{tabular}{lcccc}
\hline & \multicolumn{2}{c}{1997} & \multicolumn{2}{c}{2000} \\
\hline Education & Male & Female & Male & Female \\
0-6 years & & & & \\
(sample size) & 21.4 & 7.5 & 25.3 & 10.0 \\
7-9 years & $(182)$ & $(264)$ & $(356)$ & $(520)$ \\
(sample size) & 37.3 & 30.7 & 47.9 & 26.2 \\
10+ years & $(158)$ & $(75)$ & $(307)$ & $(141)$ \\
(sample size) & 18.2 & 25 & 38.5 & 28 \\
& $(44)$ & $(8)$ & $(104)$ & $(25)$ \\
Age & & & & \\
$16-25$ & & & & \\
& 45.9 & 30.3 & 44.2 & 27.6 \\
$26-35$ & $(122)$ & $(109)$ & $(215)$ & $(196)$ \\
& 37.6 & 8.7 & 47.8 & 15.5 \\
$36-45$ & $(93)$ & $(103)$ & $(201)$ & $(207)$ \\
& 14.0 & 4.0 & 39.3 & 8.1 \\
$46+$ & $(86)$ & $(76)$ & $(168)$ & $(160)$ \\
& 3.2 & 0 & 10.7 & 2.5 \\
& $(93)$ & $(71)$ & $(225)$ & $(163)$ \\
\hline
\end{tabular}

Notes

(i) Migration is defined as spending any time living and working outside the township in the past year.

(ii) The sample includes household member who lived for at least 6 months at home over the past year. 
Table A4

Most Important Factor Affecting Migration Decisions (percent)

\begin{tabular}{|c|c|c|c|c|}
\hline & \multicolumn{2}{|c|}{ Men } & \multicolumn{2}{|c|}{ Women } \\
\hline & $\begin{array}{l}\text { Men in } \\
\text { general }\end{array}$ & $\begin{array}{l}\text { Own } \\
\text { decision }\end{array}$ & $\begin{array}{l}\text { Women in } \\
\text { general }\end{array}$ & $\begin{array}{l}\text { Own } \\
\text { decision }\end{array}$ \\
\hline $\begin{array}{l}\text { Not enough money for transportation and } \\
\text { search costs }\end{array}$ & 14.11 & 9.03 & 8.08 & 9.65 \\
\hline Lack of information and social networks & 18.26 & 17.13 & 6.73 & 8.71 \\
\hline Not accustomed to urban lifestyle & 3.11 & 1.85 & 0.58 & 0.24 \\
\hline Local income levels are high & 2.49 & 2.78 & 2.5 & 1.65 \\
\hline Cost of living too high in urban areas & 1.66 & 1.16 & 0.38 & 0.71 \\
\hline Not enough education or skills & 25.31 & 20.83 & 12.69 & 16.47 \\
\hline Unwilling to separate from children & 3.32 & 10.88 & 46.15 & 31.53 \\
\hline Agricultural labor requirements & 25.93 & 31.25 & 20.96 & 25.88 \\
\hline $\begin{array}{l}\text { Lack of employment or education, health or } \\
\text { other public services because no urban } \\
\text { residence permit }\end{array}$ & 1.87 & 1.38 & 0.38 & 0 \\
\hline $\begin{array}{l}\text { Local government assistance in migrating to } \\
\text { urban areas }\end{array}$ & 2.07 & 1.62 & 0.38 & 0 \\
\hline $\begin{array}{l}\text { Assistance of urban government in migrating to } \\
\text { urban areas }\end{array}$ & 1.87 & 2.08 & 1.15 & 5.18 \\
\hline Number of observations & 482 & 432 & 520 & 425 \\
\hline
\end{tabular}

Notes

(i) The responses are from individual surveys of all adults in the rural households surveyed.

(ii) Individuals were asked to choose the most important barrier to migration among the set of choices presented in the table. 